\title{
Determinants of SMEs employees' creativity and their impact on innovation at workplace
}

\author{
Sania Khan ${ }^{a^{*}}$ and Mohamed Mohiya ${ }^{a}$
}

${ }^{a}$ College of Business Administration, Prince Sattam Bin Abdulaziz University, Al Kharj, Saudi Arabia

\section{CH R O N I C L E}

Article history:

Received: June 30, 2020

Received in revised format:

June 302020

Accepted: July 12, 2020

Available online:

July 23, 2020

Keywords:

Employee creativity

Workplace innovation

Workplace environment

Employee productivity

Employee competencies

\section{A B S T R A C T}

Employees being prolific in the workplace is equally essential to survive in the global job market. The study projected to identify various driving factors of employee creativity and proposed a theoretical model and further investigated the impact of independent variables on employee innovation. Using the survey questionnaire, primary data from 246 small and medium enterprises (SME) employees of Saudi Arabian organization was collected. Exploratory factor analysis (EFA) underlined the identified determinants into six causal factors namely training and brainstorming session (TBS), employee recognition and reward (ERR), resources and fund allocation (RFA), employee competencies (EC), workplace environment (WE) and management support (MS). Subsequently, multiple linear regression analysis was conducted to examine the influence of these factors on employee innovation (EI). Findings showed the regression model was significant and explained $84.2 \%$ of the variance on the dependent variable. Also, all six constructs resulted significant positive relationships with EI. Results showed EC has the highest positive relation with EI. The study demonstrated a better working environment, collaboration, team spirit, work autonomy, and morale will reinforce creativity with the support of management and allocation of resources and funds. Lack of these elements will ruin the work culture and thereby the workplace innovation. Though the results are presented from a small group and with no generalization, the study sheds light on many employees in creating a competitive edge and flourish with new opportunities by encountering uncertainties using new approaches at work. The findings are consistent and the study reconfirms the literature. The study also provides some indirect inferences to organizational human resource (HR) policymakers. Further, the limitations and future research scope were also well demonstrated.

\section{Introduction}

The ability of employees to be creative and innovative demonstrates the organization's capability to survive and flourish in this modern corporate world. The literature argues, while the organization's success is ambivalent and depends on the external environment like economic deviations, change in value and demanding competencies, the establishments must trust on their personnel ability of innovative (Lieberman \& Montgomery, 1998; Utterback, 1994; Henderson \& Clark, 1990). In understanding how to facilitate organization-wide creativeness and maximum utilization of the employees, most of the researchers understood the patterns among the employees' attitudes and behavior which are characterized under organizational climate (Becker \& Gerhart 1996; Wright, McMahan and McWilliams 1994; Mumford, 2000; Martins \& Terblanche 2003; McLean, 2005). In simple words, it is the work environment that is conducive for workplace creativeness and innovation. Many authors interpret the terms "creativity" and "innovativeness" in different ways. Woodman (1993) elucidated creativity is seen as the generation of an idea and maybe limited when a particular problem arises. It can be from doing anything for the first time or generating novel information in a particular field. On the other side, Mumford et al. (2002) recognized innovation as a series of processes right from problem identification, creating new ideas, evaluation, and implementing them. Though these two * Corresponding author.

E-mail address: saniakhan05@gmail.com (S. Khan) 
terms are used interchangeably, they are differentiated as former denoting the generation of ideas and the latter as an application of these ideas in progression with some evaluation and implementation process. So being creative is considered to be the prerequisite for innovation. While creative work environment does not happen just by a chance, most of the innovative firms in the world deliberately aspire to institutionalize and sustain a creative work environment as one of the important capabilities along with realistic work processes and fair leadership practices. Most of the research studies were emphasized in identifying the role of various HR dimensions in the workplace. Some studies explored the impact of HR practices on employees' creativity and innovativeness (Panigrahy \& Pradhan, 2015; Ghosh, 2015) while few other stressed on a conceptual model of workplace creativity in specific industry (Azeem et al., 2019) other studies discretely understood the impact and associations of the HR determinants on workplace creativity (Becker \& Gerhart 1996; Wright, McMahan \& McWilliams 1994). Although most of the studies focused on business and organization perspectives, employee dimension and workforce management are missing. Also, there are rare studies in Saudi Arabia on creativity and innovation from employees' context. However, there exists a research gap in understanding if the casual factors of employee creativity drive employee innovation or not, and what are their significant relationships among the variables. Towards filling this gap, the present study identifies influencing factors of creativity and investigates their impact on employee innovation.

This paper is outlined in seven sections. Firstly, it presents the background followed by extant literature review in section 2 . In third section data analysis using multiple linear regression analysis is demonstrated. Section 4 deals with findings and discussion followed by managerial implications in section 5. Finally, limitations in section 6 and conclusions in section 7 were presented.

\section{Literature review}

While initiating the plans to boost employee's innovativeness there are certain factors an organization must propel strategically in its regular HR practices. Looking at different HR aspects, Dougherty (1996) assured the firm's innovative success is organized by flexibility-control tensions. While flexibility drives creativity and boosts innovation, control affords self-control, and initiates innovative activities. Perceiving most of the jobs as complex in nature and challenging, employees need to be involved in problem-solving, decision making at least in their unit level to foster the positive climate of being creative at work. Allowing the employees to work discretely based on their abilities, experiences, and ideas will also help them to work at pace in an autonomous environment by sharing their knowledge among their peers. This kind of work style can cultivate trust and open communication (Masih et al., 2018; Nemeth, 1997). To be creative the employee is expected to have sufficient time to explore, generate, and develop new ideas. Also, sometimes they necessarily need to have the willingness to take the risk in experimenting with new ways of doing work irrespective of being successful or failure. Therefore, the immediate supervisors and higher management must support and accept minor failures with losses incurred at work and create a synergic and amiable culture to inculcate the innovative work culture which may save future costs of the organization. Mumford (2000), Carmeli (2005) and Hartmann, (2006) asserted that in the modern world, organizational culture directly affects employee behavior to great extent and acts as the most influential factor for employees' innovativeness. Galbraith (1984) revealed a good HR system will involve its employees in the complete innovation process because of two reasons. The first one is the firm's ability of innovation relies on the intellectual, and beliefs of its workforce (Mumford, 2000) and the second is the firm exclusively needs the employees" support in the advancement and execution phases of innovation (Vrakking, 1990). This statement was also reaffirmed by Wright and Snell (1998) and MacDuffie (1995) stating the organization performance is interlinked with the HR system, employee's enthusiasm, and competencies. Lau and Ngo (2004) pointed out training and development, recognition of employee performance, and appropriate reward system; team spirit and group dynamics promote the pioneering HR practices. Training and development align the employees' skills to achieve individual and business objectives. Sparkes and Miyake (2000) recommended training provides an opportunity for self-development and creates a knowledge-sharing environment among their peers. On the controversy, Jianwu et al. (2012) argued that rewards, teamwork are positively associated with employee creativity but training and performance appraisal are not significantly related. Similarly, Githii (2014) conveyed only training and mentoring employees will not help in innovation but reward system, communication, and exchange of thoughts, developing trust and rapid feedback with peers and superiors can expand innovation culture in the organization. So, employees will be more motivated when their performance is recognized and rewarded. The rewards can be either extrinsic like financial rewards or intrinsic rewards which gives internal satisfaction. Park et al., (2003) proved HR practices associated with the reward system will have a significant effect on the organization's performance which is also further arbitrated by HR competencies. Team spirit is vital in creating an innovation- oriented environment. Claver et al. (1998) suggested a firm must include independence, encourage group work, and introduce technology in its HR systems. Other studies echoed team development serves as an important source for innovation. This improves talent mobilization, open communication, and deploys diversified talents across the organization (Dunphy \& Bryant, 1996; Chacko \& Wacker 2001). Panigrahy and Pradhan (2015) in their study stressed many other factors like a challenging job, job rotation, involving employees in decision making, diversifying workgroups, support from supervisors, empowering employees, leaders and management supports contributes employees to exhibit creative behavior and encourages innovation in the organization. Von Krogh et al., 2000 explained developing trust in employees and showing care will elicit transparent communication, share information, and creative outcomes. Ghosh (2015) revealed behavior-oriented approaches, employee's productive thoughts, the creative work environment will reinforce the employee's creativity and further leading them to innovation. Amabile et al. (1996) and Woodman et al. (1993) developed the "componential theory model" and "interactionist model" respectively related to the work environment and 
demonstrated these frameworks can boost personnel creativity. Dul and Ceylan (2011) comprehensive study on work environment identified various socio-organizational factors like conditions on job design, employees' joint effort, governance styles, and reward system. These factors were described at three different levels viz., organization level, team level, and at job level with corresponding sub-levels under each and illustrated a positive work attitude may be moderated or arbitrated by the connection amid socio-organizational atmosphere and creativeness (Shalley et al., 2004). All these elements help employees to recognize challenges at a job with the power of autonomy.

In exploring different practices of knowledge management and its effect on innovative performance, Githii (2014) argued that knowledge management maneuvers creative thoughts. Based on the ease of policies and strategies formulated by leaders the innovation can be upsurge or declined. However, centralized leadership and management support can directly influence the innovation process. Utami (2013) articulated only sharing earlier experiences will not encourage product innovation, but also moderated by transformational leadership style and focus group discussion among employees can actually employees intellectually. In modern world information technology is an integral part of an organization in many aspects. Kaewchur et al. (2013) stressed tactics and clear knowledge are essential to enhance product and service innovation and such information familiarity is gained by technological adoption and capitalizing on research and development activities. Similarly, Masih N. et al., 2018 in their research study explicitly presented various factors that affect employee innovation and knowledge sharing but not limited to leadership policies and strategies, HR systems, information technology, training programs, reward system, intellectual stimulation, and culture of innovation at work. Six determinants namely training and brainstorming sessions, employee recognition and reward, resources and fund allocation, employee competencies and workplace environment, and management support were identified from the literature.

\subsection{Model Development and Formulation of Research Hypotheses}

Based on the identified factors through retrospective literature, the below conceptual model was developed as shown in figure 1. Training is a part of the knowledge transfer process that develops and sophisticates' employees' knowledge and skills; changes their behavior and aligns their efforts in achieving organizational goals. Previous studies underpinned that brainstorming sessions to the employees could improve the product innovation and business process and such meetings sometimes are very reliable and beneficial rather than seeking advice from outside experts. Also, training programs will lay off the skills deficiency where organizations must carefully assign resources on such programs to retain skilled manpower (Lau \& Ngo, 2004; Jaithern Abdullah et al., 2019). Therefore, it is hypothesized as below.

$\mathbf{H}_{1}$ : TBS will have a direct positive effect on EI at work.

Recognizing the employee's performance and rewarding them will act as a catalyst in a widespread culture of innovation and would bring job satisfaction by self-indulgence (Githii, 2014; Lau \& Ngo, 2004; Masih et al., 2018). Rewards may include both intrinsic or extrinsic. It can be a powerful tool to motivate employees and must be utilized effectively to attract the best performers. It will encourage employees to strive for higher achievement, generate smart ideas, and think creatively, but ignoring rewards would discourage people and weaken their drive to creativity (Ndaliman et al., 2013; Lee \& Miller, 1999). Management with attracting funds and rewards could encourage manpower creativity and mediates development culture. Forcing people to present creative ideas at certain times will not bring true innovation (Lau \& Ngo, 2004). Rather they must think about how to reward people who embody "improvement" or "creativity?" and develop an appropriate reward system. At the same time rewarding in money form will ultimately develop employee dissatisfaction as they anticipate additional and higher recompense and subsequently lead no best outcomes to the business (Amabile et al., 1996). Therefore, a proper performance appraisal system must recognize an individual's contribution and more importantly with a total value proposition of a job, which includes not only financial rewards but also prospects for personal and professional growth. Therefore, it is hypothesized as below.

\section{$\mathbf{H}_{2}$ : ERR will have a direct positive effect on EI at work.}

Giambatista and Bhappu (2010) examined the combined influence of other sources like communication technology, openness, ethnic diversity, and found the growth in creative ideas among the workforce. The need to create a more skilled workforce for employment in high-performance workplaces producing high quality and high-value products and services has become an important priority for many organizations. Lau and Ngo (2004) clarified, this is possible when the firms allot dedicated resources and budget for addressing training requirements to adapt changes and funds for research and development. Hence it is hypothesized that

\section{H3: RFA will have a direct positive effect on EI.}

Employees are considered to be the greatest assets and resources for any organization. No organization can grow extraordinary without projecting people's competencies. Dougherty 1996, also portrayed flexibility-control tensions influences on fundamental capabilities in accomplishing longstanding goals of an organization. Generating creative ideas by employees worth more than financial assets for an organization. Nemeth, 1997 asserted creativity begins by posing questions, breaking the boundaries, and considering things by thinking out of the box. Therefore, an appropriate recompense scheme must be implemented for innovative employees which can motivate them in displaying creative behavior (Mabey \& Salaman, 1995). Therefore, it is hypothesized as below. 
H4: EC will have a direct positive effect on EI.

Most of the extant literature highlighted on the work culture and work environment to inculcate innovation at work and stated more relaxed and tranquil environment will result in innovation (Amabile et al., 1996; Woodman et al., 1993; Shalley, 2004; Masih et al., 2018; Sparkes \& Miyake, 2000). Higgins and McAllaster (2002) exposed a specific culture that is essential to showcase to bring notified changes in the organization system to support innovation. Hirst, Van Knippenberg, and Zhou (2009) emphasized learning orientation and found it has a strong positive effect on creativity. So, encouraging individuals to make decisions and learn from their mistakes fosters a creative environment, especially when coupled with a "team-first" attitude. In this context, management will have a vital role in mediating the employees' creativity by developing a friendly workplace environment. Therefore, it is hypothesized as below.

H5: WE will have a direct positive effect on EI.

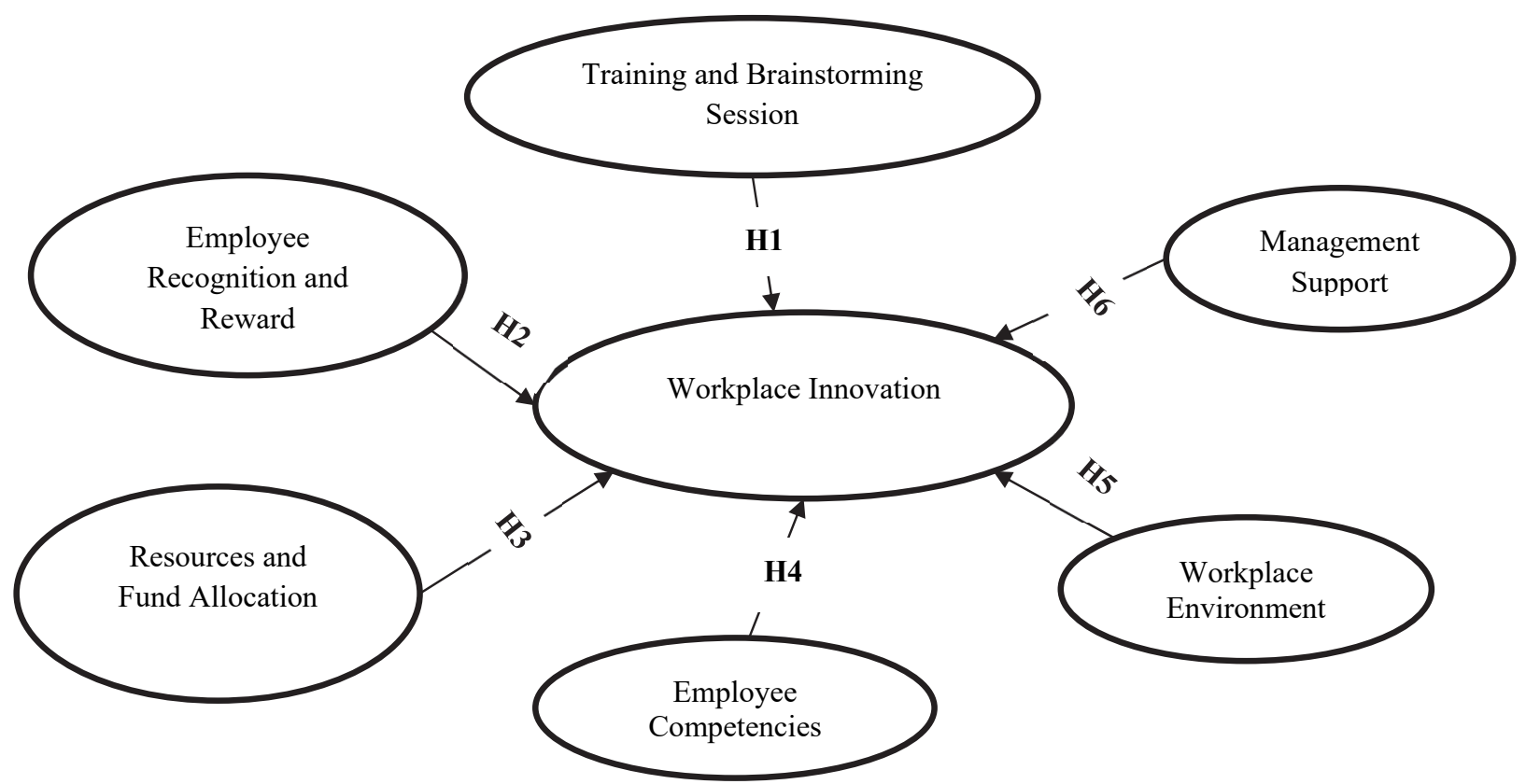

Fig. 1. A proposed theoretical model of employees' creativity and innovation at workplace

Leadership style and management support are the backbones for any organization in bringing any kind of change by strictly institutionalizing the HR activity. Panigrahy and Pradhan (2015) endorsed that there must be a proper deployment of diversified talents to spread a learning and innovative culture by the management. Sweetman (2001) and Ahmed, (1998) recommended the strategies to encourage work environment by managerial support and found managerial support acts as an arbitrary either in supporting or obstructing the innovation inside the organization. O'Reilly (1997) suggested a noble innovative thought is a fragile character that will be suppressed due to the absence of proper organizational structure, motivation, and self-confidence. Therefore, management support plays a vital role and influence EI. Hence it is hypothesized as below.

H6: MS will have a direct positive effect on EI.

\section{Methodology}

\subsection{Survey Instrument and Data Collection}

This section presents the development of the survey instrument and data collection. The questionnaire used the five-point Likert-scale with eighteen measurement items of the respective constructs. The SME in Saudi Arabia contributes to the majority of employment opportunities and constitutes a huge talent pool from different nations. Therefore, the study collected primary data from 246 SME organization employees from the Riyadh region using a well-developed questionnaire with both closed and few open-ended questions in the English language. The sample consists of 46.8 percent of female and 53.2 percent male respondents including both Saudi (43.8\%) and non-Saudi (56.2\%) employees. All employees are within the age group of 20 to 50 years and most of them are with a bachelor's degree. Table 1 illustrates the demographic profile of the respondents. The study was conducted in two folds. Firstly, exploratory factor analysis (EFA) was conducted using principal component analysis (PCA) under varimax rotation. Next SPSS (version 21) software was used for data analysis using multiple linear regression. 
Table 1

Demographic Summary of the Respondents

\begin{tabular}{|c|c|c|}
\hline Demographics & & Per cent $(\mathrm{N}=246)$ \\
\hline \multirow[t]{2}{*}{ Gender } & Male & 53.2 \\
\hline & Female & 46.8 \\
\hline \multirow[t]{3}{*}{ Age (years) } & $20-30$ & 12.4 \\
\hline & $31-40$ & 45.2 \\
\hline & $41-50$ & 42.4 \\
\hline \multirow[t]{2}{*}{ Education } & Bachelor Degree & 72.6 \\
\hline & Masters and Above & 27.4 \\
\hline \multirow[t]{2}{*}{ Nationality } & Saudi & 43.8 \\
\hline & Non-Saudi & 56.2 \\
\hline
\end{tabular}

Source: Primary Data Analysis

\subsection{Exploratory Factor Analysis and Reliability}

Firstly, factor analysis was conducted to investigate the dimensionality of the developed scale with measurement items and the constructs, TBS ( 3 items), ERR ( 2 items), RFA (3 items), EC ( 2 items), WE (4 items), MS (4 items). Table 2 demonstrates Bartlett's test of sphericity was significant with $\mathrm{p}<0.000$ and the Kaiser-Meyer-Olkin value was 0.816 which fulfilled the factorability conditions (Coakes \& Steed, 2003) and extracted all the items into six underlying factors based on the Eigenvalue greater than 1 . The Cronbach alpha coefficient checks the factor reliability and is above 0.60 for each construct (Nunnally, 1978) in fact between the range of 0.721 to 0.842 . Also, the factor loadings are all above 0.50 (Hair et al., 2006). Among all the constructs, EC has explained 47.62 percent of variance and the least is ERR with 11.54 percent.

Table 2

Results of EFA

\begin{tabular}{|c|c|c|c|}
\hline Construct & $\begin{array}{l}\text { Factor } \\
\text { Loadings }\end{array}$ & $\begin{array}{l}\text { Cronbach } \\
\text { Alpha }(\alpha)\end{array}$ & $\begin{array}{l}\text { \% of Variance } \\
\text { Explained }\end{array}$ \\
\hline \multicolumn{2}{|l|}{ Training and Brainstorming Session (TBS) } & \multirow{4}{*}{0.783} & \multirow{4}{*}{$13.47 \%$} \\
\hline I share work-related information among my peers (TBS1) & 0.765 & & \\
\hline I am interested to participate in knowledge gaining sessions for career advancement $\&$ growth & 0.737 & & \\
\hline The training program provides an opportunity for self-development (TBS3) & 0.836 & & \\
\hline \multicolumn{2}{|l|}{ The training program provides an opportunity for self-development (TBS3) } & \multirow{3}{*}{0.721} & \multirow{3}{*}{$11.54 \%$} \\
\hline Training and Brainstorming Session (TBS) & 0.739 & & \\
\hline Extra incentive motivates my creativity at work (ERR2) & 0.844 & & \\
\hline \multicolumn{2}{|l|}{ Resources and Fund Allocation (RFA) } & \multirow{4}{*}{0.831} & \multirow{4}{*}{$21.83 \%$} \\
\hline My organization mobilize talents to energize creativity in employees (RFA1) & 0.878 & & \\
\hline $\begin{array}{l}\text { My organization build reputational mechanism at all levels to simplify and streamline the busi- } \\
\text { ness process (RFA2) }\end{array}$ & 0725 & & \\
\hline My organization is committed to the deployment of new technology (RFA3) & 0.825 & & \\
\hline \multicolumn{2}{|l|}{ Employee Competencies (EC) } & \multirow{3}{*}{0.797} & \multirow{3}{*}{$47.62 \%$} \\
\hline I develop my work competencies and stay sophisticated (EC1) & 0.817 & & \\
\hline I apply new methods in solving work-related problems (EC2) & 0.798 & & \\
\hline \multicolumn{2}{|l|}{ Workplace Environment (WE) } & \multirow{6}{*}{0.805} & \multirow{6}{*}{$18.74 \%$} \\
\hline Autonomy at work promotes individual creativity (WE1) & 0.882 & & \\
\hline $\begin{array}{l}\text { I have a good working environment at work which allows open communication on work-related } \\
\text { matters (WE2) }\end{array}$ & 0.853 & & \\
\hline Better working environment, collaboration, and morale spread innovative thoughts (WE3) & 0.871 & & \\
\hline Team spirit will create a good work environment and spreads the culture of innovation (WE4) & 0.868 & & \\
\hline \multicolumn{2}{|l|}{ Management Support (MS) } & & \\
\hline My management empowers employees and develops trust (MS1) & 0.786 & \multirow{4}{*}{0.842} & \multirow{4}{*}{$24.80 \%$} \\
\hline Employees while creating competitive edge will flourish with new opportunities at work (MS2) & 0.774 & & \\
\hline My organization deploys diversified talents to instill creativity and learn new things (MS3) & 0.884 & & \\
\hline A good HR system will motivate employees to be creative (MS4) & 0.914 & & \\
\hline
\end{tabular}

\subsection{Multiple Linear Regression}

To address various research questions, the study applied multiple linear regression analyses to assess the relationship between independent and dependent variables. Based on the results of EFA and the variance explained by the variables, the determinants emerged into six underlying factors. The regression model resulted statistically significant which explained 84 percent $\left(\mathrm{R}^{2}\right)$ of the total variance and a significant $\mathrm{F}$-value of 41.152 at $\mathrm{P}<0.000$. Table 3 and Table 4 correspondingly demonstrate the regression model summary and ANOVA model. The results of the regression model are consistent with the literature review and found a direct significant positive impact on EI. Among all EC found to have a strong significant positive relation with creativity and innovation with $\beta=0.439$ and the least positive is $\beta=0.262$ for MS. After diagnosing, scores of variance inflation factor (VIF) and tolerance were within the threshold limit representing no possibility of multi-collinearity (Hair et al., 2006). Table 5 displays the coefficient correlations between independent and dependent variables. 
Table 3

Model Summary

\begin{tabular}{lllll}
\hline Model & $\mathrm{R}$ & $\mathrm{R}^{2}$ & Adjusted $\mathrm{R}^{2}$ & Std. Error of the Estimate \\
\hline 1 & $0.857^{\mathrm{a}}$ & 0.842 & 0.821 & 2.184 \\
\hline
\end{tabular}

Source: Primary data analysis

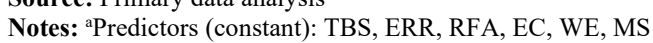

Table 4

ANOVA Model

\begin{tabular}{lllll}
\hline Model & Sum of Squares & df & Mean Square & F \\
\hline Regression & 19.864 & 6 & 9.932 & 41.152 \\
Residual & 79.943 & 79 & 3.561 & $0.000^{*}$ \\
\hline Total & 99.807 & 85 & & \\
\hline
\end{tabular}

Source: Primary data analysis

Notes: "Predictors (constant): TBS, ERR, RFA, EC, WE, MS

Dependent variable: Employee creativity \& innovation

Table 5

Coefficients

\begin{tabular}{|c|c|c|c|c|c|c|c|}
\hline \multirow[t]{2}{*}{ Model } & \multicolumn{2}{|c|}{$\begin{array}{c}\text { Unstandardized } \\
\text { Coefficients } \\
\end{array}$} & \multicolumn{2}{|c|}{$\begin{array}{c}\text { Standardized } \\
\text { Coefficients }\end{array}$} & \multirow[b]{2}{*}{ Sig. } & \multicolumn{2}{|c|}{$\begin{array}{c}\text { Collinearity } \\
\text { Statistics } \\
\end{array}$} \\
\hline & B & Std. Error & B & $\mathbf{t}$ & & Tolerance & VIF \\
\hline 1 (Constant) & 1.865 & 0.269 & & 4.552 & 0.017 & & \\
\hline EC & 0.412 & 0.058 & 0.439 & 6.041 & 0.000 & 0.657 & 1.520 \\
\hline ERR & 0.394 & 0.072 & 0.410 & 6.085 & 0.000 & 0.610 & 1.638 \\
\hline WE & 0.248 & 0.073 & 0.348 & 4.281 & 0.002 & 0.889 & 1.124 \\
\hline TBS & 0.265 & 0.064 & 0.290 & 3.429 & 0.001 & 0.698 & 1.432 \\
\hline RFA & 0.184 & 0.062 & 0.312 & 3.621 & 0.005 & 0.720 & 1.387 \\
\hline MS & 0.209 & 0.045 & 0.262 & 2.932 & 0.008 & 0.829 & 1.206 \\
\hline
\end{tabular}

Source: Primary data analysis

Notes: Dependent variable: Employee creativity \& innovation

\section{Findings and discussion}

The findings exposed that overall EI.is positively affected by the number of determinants. EFA exposed the presence of six underlying factors namely TBS, ERR, RFA, EC, WE, and MS, that have a vital role in EI. Among all the predictors, EC $(\beta=$ $0.439)$ at $p<0.001$ is the most significant predictor of EI. Facing challenges requires the utilization of human mental resources. Therefore, employees must develop their competencies and stay competitive. This will empower them with the capacity to think of old problems and mitigate in new ways, to change longstanding perspectives, or to create novel and useful approaches. ERR has obtain the second-highest positive correlation with $\beta=0.410$ at $p<0.001$. Employees must be recognized for their innovation and rewarded correspondingly. This may increase their confidence level and morale at work. Further, the employees will be able to look at various problems and mitigate them by applying new methods. Thus, the productive employees will develop self-confidence, job satisfaction, and thus facilitate employer to retain quality employees. This inspiration will bring positive energy in the employees with increased interaction and engagement at work in support of the management. TBS has a moderate significant effect on EI with $\beta=0.290$ at $\mathrm{p}<0.001$. Respondents believe training is a human capital investment that every organization needs to invest in their employees to facilitate learning and self-development. It creates an environment of knowledge sharing among peers and provides an opportunity to learn from each other. This illustrates that training and brainstorming sessions must be well organized with proper allocation of resources and budget to promote creativity. This shows that brainstorming sessions are those which promote employees to exchange ideas and generate multiple ideas for one particular problem. Such sessions could be of great fun and learning-oriented. Therefore, it is recommended to conduct such gatherings between supervisors and work teams to derive new thoughts with better interaction between top-down and vice versa hierarchies. RFA is moderate positive relation on EI with $\beta=0.312$ at $p<0.001$, explains the organization needs to critically examine the modern management strategy and invest in internal structure, maximize human resource talents and build reputational mechanism at all levels to simplify and streamline the business process. Management must also persist mobilizing talent, allocating resources, formulate new strategies and implement suitable business models to fuel future success along by understanding if there is adequate training to exploit technology required for the work. If management is more centered on control and efficiency through implementing new procedures, workplace creativity will be truncated. MS resulted in least positive relationship with $\beta=0.262$ at $p<0.00$. It illustrates the most of the SME organizations in Saudi Arabia do not support their employees for creativity but may look for some other aspects from employees.

\section{Managerial implications}

This study attempted to identify the determinants of employees' workplace creativity and innovation. The study is imperative in understanding the influence and relationships among various independent and dependent variables. The findings of this study will help the employees and top management to overcome the traditional practices and barriers that are impeding them towards bringing out the best in them and strategically formulate a better work culture for their human resource to a great extent. Further, the top management and leaders at various department levels can emphasize on privileging employees with 
training programs, brainstorming and interactive sessions, develop recognition and reward programs for the best performers by properly maintaining and centralizing the performance management system. Such activities can enable the employees to develop work autonomy and progress them intellectually by improving the work culture through involving themselves in the idea and knowledge sharing among their peers, exploit skills and fetch new methods in doing tasks. Further organizations can develop new methods of compensation for employees like performance-based pay. Also, the study contributes to workplace creativity and innovation literature, academic researchers, and organizations that deal with these concepts.

\section{Limitations and scope of future research}

The data collected for the study is a cross-sectional type obtained from various employees of SME organizations. Therefore, the findings may be restricted to SME firm's work culture, learning, and innovativeness. Therefore, further researchers could conduct comparative analysis or include more employees from big organizations to generalize the findings. Also conducting similar studies in different nations could help in understanding the work culture, work environment, and management strategies in supporting their respective employee creativity and innovative behavior. Also, some other theoretical models can be developed based on other qualitative approaches. More interestingly, researchers may study the competency gaps and barriers that hindering the employees' creativity and innovation.

\section{Conclusion}

The purpose of this study was to identify various driving factors that are driving employees directly in the progression of being creative and innovative at work and propose a theoretical model. Further, it aimed to validate the developed model using primary data from employees of SME. The findings demonstrated employee creativity helps them to generate new ideas and address the problems in new ways. Further implementing these creative ideas will motivate them to innovate new products, services, and business processes which will give a feeling of self-satisfaction, work enthusiasm, and develops collaboration and team spirit. It provides a deep insight to employees on how to improve themselves and meet the future demanding competencies. On the other hand, it can further address the future managerial concerns of gap analysis and mitigate the crises of the talent search. The findings and discussions are well documented in previous sections followed by managerial implications, limitations, and future scope of the study.

\section{Acknowledgments}

The authors would like to express special thanks to all the respondents who participated in this research and also to the reviewers for their constructive comments which helped in improving the quality of this research article.

\section{References}

Al Harbi, J. A., Alarifi, S., \& Mosbah, A. (2019). Transformation leadership and creativity. Personnel Review, 48(5), 10821099.

Amabile, T. M., Conti, R., Coon, H., Lazenby, J., \& Herron, M. (1996). Assessing the work environment for creativity. Academy of Management Journal, 39(5), 1154-1184.

Azeem, M., Mataruna-Dos-Santos, L. J., Moalla, R. B. A., \& Kaleem, M. M. (2019). Confirmatory model of the workplace creativity in higher education. International Journal of Recent Technology and Engineering, 8(2), 426-425.

Becker, B., \& Gerhart, B. (1996). The impact of human resource management on organizational performance: Progress and prospects. Academy of Management Journal, 39(4), 779-801.

Carmeli, A. (2005). The relationship between organizational culture and withdrawal intentions and behavior. International Journal of Manpower, 26(2), 177-95

Chacko, T. I., \& Wacker, J. G. (2001). An examination of strategic goals and management practices of Russian enterprises. International Business Review, 10(4), 475-490.

Claver, E., Llopis, J., Garcia, D., \& Molina, H. (1998). Organizational culture for innovation and new technological behavior. The Journal of High Technology Management Research, 9(1), 55-68.

Coakes, S., \& Steed, L. (2003). SPSS analysis without anguish: Version 11.0 for Windows. Melbourne: Wiley.

Dougherty, D. (1996). Organizing for innovation. In: Clegg, S.R., Handy, C., Nord, W.R. (Eds.), Handbook of Organization Studies. Sage, Thousand Oaks, CA, pp. 424-439.

Dul, J., \& Ceylan, C. (2011). Work environments for employee creativity. Ergonomics, 54(1), 12-20.

Dunphy, D., \& Bryant, B. (1996). Teams: panaceas or prescriptions for improved performance?. Human relations, $49(5), 677-$ 699.

Galbraith, J. R. (1984). Human resource policies for the innovating organization. Strategic Human Resource Management, 319-341.

Ghosh, K. (2015). Developing organizational creativity and innovation. Management Research Review, 38(11), 1126-1148.

Githii, S. (2014). Knowledge management practices and innovation performance: a literature review. Journal of Business and Management (IOSR-JBM), 16(2), 89-94.

Hair, J., Black, B., Babin, B., Anderson, R.E., \& Tatham, R.L. (2006). Multivariate data analysis (2 ${ }^{\text {nd }}$ ed.). Upper Saddle River, NJ: Pearson/Prentice Hall. 
Hartmann, A. (2006). The role of organizational culture in motivating innovative behaviour in construction firms. Construction Innovation, 6(3), 159-72.

Henderson, R. M., \& Clark, K. B. (1990). Architectural innovation: The reconfiguration of existing product technologies and the failure of established firms. Administrative Science Quarterly, 35, 9-30.

Jiang, J., Wang, S., \& Zhao, S. (2012). Does HRM facilitate employee creativity and organizational innovation? A study of Chinese firms. The International Journal of Human Resource Management, 23(19), 4025-4047.

Kaewchur, O., Anussornnitisarn, P., \& Pastuszak, Z. (2013). The mediating role of knowledge sharing on information technology and innovation. International Journal of Management, Knowledge and Learning, 2(2), 227-242.

Lau, C. M., \& Ngo, H. Y. (2004). The HR system, organizational culture, and product innovation. International Business Review, 13(6), 685-703.

Lee, J., \& Miller, D. (1999). People matter: commitment to employees, strategy and performance in Korean firms. Strategic Management Journal, 20, 579-593.

Lieberman, M. B., \& Montgomery, D. B. (1988). First-mover advantages. Strategic Management Journal, 9(S1), 41-58.

Mabey, C., \& Salaman, G. (1995). Strategic Human Resource Management. London: Blackwell.

MacDuffie, J. (1995). Human resource bundles and manufacturing performance: organizational logic and flexible production systems in the world auto industry. Industrial and Labor Relations Review, 48, 197-221.

Martins, E., \& Terblanche, F. (2003). Building organizational culture that stimulates creativity and innovation. European Journal of Innovation Management, 6(1), 64-74.

Masih, N., Sriratanaviriyakul, N., El-Den, J., \& Azam, S. (2018, June). The Role of Knowledge Sharing on Employees' Innovation Initiatives. In 2018 8th International Workshop on Computer Science and Engineering, WCSE 2018 (pp. $697-$ 704). International Workshop on Computer Science and Engineering (WCSE).

McLean, L. D. (2005). Organizational culture's influence on creativity and innovation: A review of the literature and implications for human resource development. Advances in Developing Human Resources, 7(2), 226-246.

Mumford, M. D. (2000). Managing creative people: Strategies and tactics for innovation. Human Resource Management Review, 10(3), 313-351.

Mumford, M. D., Scott, G. M., Gaddis, B., \& Strange, J. M. (2002). Leading creative people. Orchestrating expertise and relationships Leadership Quarterly, 13, 705- 750.

Ndaliman, M. A., Kamariah, I., Chikaji, A. I., \& Mohd, K. R. (2015). Exploring employee motivation and creativity on SMEs innovation implementation activities in Nigeria. Global Journal of Business and Social Science Review, 1(1), $156-162$.

Nemeth, C.J. (1997). Managing innovation: when less is more. California Management Review, 40(1), 59-74.

Nunnally, J.C. (1978). Psychometric theory. New York, NY: McGraw Hill.

O'Reilly, B. (1997). The secrets of America's most admired corporations: new ideas, new products. Fortune, 135(4), 60-64.

Pervaiz, K. A. (1998). Culture and climate for innovation. European Journal of Innovation Management, 1(1), 30-43.

Panigrahy, P.N., \& Pradhan, K.R. (2015). Creativity and innovation: Exploring the role of HR practices at workplace. Presentation of Paper at National Conference organized by Ravenshaw B-School, Cuttak.

Park, H. J., Mitsuhashi, H., Fey, C. F., \& Bjorkman, I. (2003). The effect of human resource management practices on Japanese MNC subsidiary performance: a partial mediating model. International Journal of Human Resource Management, 14, 1391-1406.

Shalley, C.E., Zhou, J., \& Oldham, G.R. (2004). The effects of personal and contextual elements on creativity: Where should we go from here? Journal of Management, 30, 933-958.

Sparkes, J. R., \& Miyake, M. (2000). Knowledge transfer and human resource development practices: Japanese firms in Brazil and Mexico. International Business Review, 9, 599-612.

Sweetman, D., Luthans, F., Avey, J. B., \& Luthans, B. C. (2011). Relationship between positive psychological capital and creative performance. Canadian Journal of Administrative Sciences, 28(1), 4-13.

Utami, M.M. (2013). How intellectual stimulation effects knowledge sharing, innovation and firm performance. International Journal of Social Science and Humanity, 3(4), 420.

Utterback, J.M. (1994). Mastering the Dynamics of Innovation: How Companies Can Seize Opportunities in the Face of Technological Change. Harvard Business School Press, Boston, MA.

Von Krogh, G., Ichijo, K., \& Nonaka, I. (2000). Enabling knowledge creation. New York, NY: Oxford University Press, Inc

Vrakking, W.J. (1990). The innovative organization. Long Range Planning, 23, 2, 94-102.

Woodman, R.W., Sawyer, J.E., \& Griffin, R.W. (1993). Toward a theory of organizational creativity. Academy of Management Review, 18(2), 293-321.

Wright, P. M., \& Snell, S. A. (1998). Toward a unifying framework for exploring fit and flexibility in strategic human resource management. Academy of Management Review, 23, 756-772.

Wright, P.M., McMahan, G.C., \& McWilliams, A. (1994). Human resources and sustained competitive advantage: A resourcebased perspective. International Journal of Human Resource Management, 5(2), 301- 326.

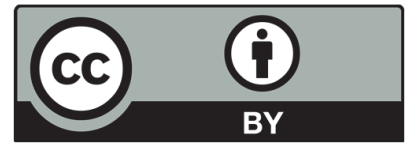

(C) 2020 by the authors; licensee Growing Science, Canada. This is an open access article distributed under the terms and conditions of the Creative Commons Attribution (CC-BY) license (http://creativecommons.org/licenses/by/4.0/). 